Article

\title{
Tailoring Mechanical Properties of Collagen-Based Scaffolds for Vascular Tissue Engineering: The Effects of pH, Temperature and Ionic Strength on Gelation
}

\section{Matteo Achilli and Diego Mantovani *}

Laboratory for Biomaterials and Bioengineering, Department of Materials Engineering \& Research Centre, Quebec University Hospital, Laval University, Pavillon Pouliot, 1745-E, Quebec City, G1K 7P4, Canada; E-Mail: matteo.achilli.1@ulaval.ca

* Author to whom correspondence should be addressed; E-Mail: diego.mantovani@gmn.ulaval.ca; Tel.: +1-418-656-2131 ext. 6270; Fax: +1-418-656-5343.

Received: 8 October 2010; in revised form: 27 October 2010 / Accepted: 2 December 2010 /

Published: 6 December 2010

\begin{abstract}
Collagen gels have been widely studied for applications in tissue engineering because of their biological implications. Considering their use as scaffolds for vascular tissue engineering, the main limitation has always been related to their low mechanical properties. During the process of in vitro self-assembly, which leads to collagen gelation, the size of the fibrils, their chemical interactions, as well as the resulting microstructure are regulated by three main experimental conditions: $\mathrm{pH}$, ionic strength and temperature. In this work, these three parameters were modulated in order to increase the mechanical properties of collagen gels. The effects on the gelation process were assessed by turbidimetric and scanning electron microscopy analyses. Turbidity measurements showed that gelation was affected by all three factors and scanning electron images confirmed that major changes occurred at the microstructural level. Mechanical tests showed that the compressive and tensile moduli increased by four- and three-fold, respectively, compared to the control. Finally, viability tests confirmed that these gels are suitable as scaffolds for cellular adhesion and proliferation.
\end{abstract}

Keywords: collagen gel; scaffolds; tissue engineering; cell viability; mechanical properties; scanning electron microscopy 


\section{Introduction}

According to the World Health Organization, cardiovascular diseases constitute one of the most important causes of mortality throughout the world [1]. When small caliber $(\varnothing<6 \mathrm{~mm})$ blood vessels have to be replaced and autologous substitutes are unavailable, synthetic grafts do not represent a long-term alternative and other options have to be considered [2-5]. Scaffold-based vascular tissue engineering (VTE) proposes to combine cells and scaffolding systems in order to obtain vascular constructs [4]. Concerning the choice of the material for the scaffolds, collagen in particular is of significant interest because of its biological properties [6,7].

The collagen family includes more than 20 types of extracellular proteins. All these types present the same molecular structure, i.e., a right-handed triple helix composed of three left-handed twists of $\alpha$-chains, where each $\alpha$-chain is a monotonously repeating sequence of amino acids (Gly-X-Y). Nearly one-third of its residues are Gly, another 15 to $30 \%$ are Pro (in X position) and Hyp or Hyl (in Y position) [8]. Collagen types III and I are fibril-forming collagens and represent the major stress-bearing component of the fibrous matrices of blood vessels [9]. These collagens assemble into well-packed, highly-orientated aggregates, which present a characteristic banding pattern with a periodicity of about $70 \mathrm{~nm}$ (the D-period) [8].

Type I collagen can be obtained from the collagen fibers of rat-tail tendons (RTT) by solubilization in acetic acid [10]. This process results in the decomposition of collagen fibers and fibrils into small aggregates of collagen monomers dispersed in the acid solution. It has been widely documented that these small aggregates undergo in vitro "self-assembly" at neutral $\mathrm{pH}$, in salt solution and at $37{ }^{\circ} \mathrm{C}$ or room temperature, forming fibrils with the typical banding pattern [11]. These gels show good biological properties and can be formed into tubular structures or into any shape suitable for further characterization $[7,12,13]$. On the other hand, the process of solubilization determines the loss of the structural organization and mechanical features of the original collagen matrix. The main drawback of collagen gel-based constructs resides in their low mechanical properties, in terms of low stiffness and low elasticity, which make them unsuitable for implantation [14]. At the same time, cell-driven remodeling of the collagen matrix under dynamic conditioning has been shown to have potential in order to overcome this limitation $[15,16]$.

Collagen fibrillogenesis depends on electrostatic and hydrophobic interactions [11,17-20]. Ionization and electrostatic interactions between amino acid residues are regulated by factors such as $\mathrm{pH}$ and ionic strength. The formation of net charges between collagen molecules of neighboring fibrils may determine electrostatic attractions that can stabilize the matrix as well as affect the size of the fibrils and consequently the structure of the matrix [20-23]. Moreover, temperature affects the hydrophobic interactions and therefore the kinetics of collagen fibrillogenesis as well as $\mathrm{pH}$ and ionic strength $[20,23,24]$.

The previously adopted protocols for collagen gels were conceived to favor the inclusion of cells in the gel as well as their proliferation and the remodeling of the collagen microstructure. This approach implies three experimental conditions: preparation of the gel solution with culture medium, gelation in the incubator and neutral $\mathrm{pH}[12,25]$. These conditions fix the ionic strength, the $\mathrm{pH}$ and the temperature at which fibrillogenesis occurs and affect the size of the fibrils, the interactions between neighboring fibrils and, consequently, the type of microstructure and the mechanical properties of the 
scaffold. The resulting tubular construct is expected to be remodeled by cellular activity within one week in static culture after which the construct is to be placed in a bioreactor for dynamic conditioning and final maturation [12]. At the same time, the gel used in this approach does not seem to be sufficiently resistant to ensure the integrity of the construct, neither during the procedures of manipulation and mounting in the bioreactor, nor during the first period of dynamic conditioning while the mechanical resistance of the construct is mainly provided by the scaffold [26]. Other works showed the possibility of associating additional supports to the collagen gel-based construct in order to preserve its structural integrity during these steps [15,27,28].

Another approach consists of seeding cells on collagen gel-based scaffolds whose mechanical properties have been increased by physical or chemical crosslinking [29].

As an alternative to improve the mechanical performances of collagen gel scaffolds without crosslinking treatments, this work aimed at tailoring and finally increasing the mechanical properties of collagen gels by modulating ionic strength, $\mathrm{pH}$ and temperature of gelation. The effects of these parameters on collagen gelation were characterized with turbidity measurements, scanning electron microscopy (SEM) and mechanical tests. Particular attention was focused on the role of $\mathrm{pH} 10$ in increasing the mechanical properties. These scaffolds were then rinsed with buffer medium in order to set the $\mathrm{pH}$ to a physiological level, cells were seeded on top and the construct incubated to favor cell proliferation. The suitability of these gels as scaffolds for vascular cells was assessed using colorimetric assays. Though not discussed in this work, an eventual tubular construct could be mounted in a bioreactor for dynamic conditioning and maturation.

\section{Experimental Section}

Collagen was obtained from RTT and solubilized at $4 \mathrm{mg} / \mathrm{mL}$ in $0.02 \mathrm{M}$ acetic acid according to a previously developed protocol [10]. Collagen gels were prepared on ice at two different pHs, with seven different salt concentrations corresponding to different ionic strengths, and gelled at three different temperatures. Collagen was mixed with different concentrations of sodium chloride $(\mathrm{NaCl}$, Sigma Aldrich, St. Louis, MO, U.S.) and $1 \mathrm{M}$ sodium hydroxide (NaOH, Laboratoire MAT Inc., Quebec City, QC, Canada). The final volume was adjusted with deionized water and the resulting solution was at $\mathrm{pH} 10$ with a collagen concentration of $2.8 \mathrm{mg} / \mathrm{mL}$. The final concentrations of $\mathrm{NaCl}$ as well as an outline of the experimental plan are presented in Table 1. Gels at $\mathrm{pH} 7$ were obtained by including Hepes (Sigma Aldrich, St. Louis, MO, U.S.) solution at a final concentration of $17 \mathrm{mM}$.

Table 1. Experimental plan for the preparation of collagen gels. Samples were prepared combining each level of each of the three factors: $\mathrm{pH}$, temperature and ionic strength. The levels of ionic strength were defined by modulating the salt concentration.

\begin{tabular}{c|ccccccc}
\hline Factors & Levels & & & & & & \\
\hline $\mathbf{p H}$ & 7 & 10 & & & & & \\
$\mathbf{T}\left({ }^{\circ} \mathbf{C}\right)$ & $4(\mathrm{~T} 1)$ & $21(\mathrm{~T} 2)$ & $37(\mathrm{~T} 3)$ & & & & \\
Salt Conc. $(\mathbf{m M})$ & $64.2(\mathrm{c} 1)$ & $82.6(\mathrm{c} 2)$ & $101(\mathrm{c} 3)$ & $119(\mathrm{c} 4)$ & $138(\mathrm{c} 5)$ & $156(\mathrm{c} 6)$ & $174(\mathrm{c} 7)$ \\
\hline
\end{tabular}


Except for turbidimetric assays, once that gelation was complete the samples were soaked overnight in phosphate-buffered saline (PBS 1×, Sigma Aldrich, St. Louis, MO, U.S.), in order to carry out the tests at physiological $\mathrm{pH}$ and ionic strength.

Collagen solutions $(200 \mu \mathrm{L})$ were poured into 96 multiwell plates (96 Well Cell Culture Cluster, Corning, NY, U.S.) and gelled at the three different temperatures. Each combination of pH, ionic strength and temperature was repeated four times $(n=4)$. While collagen solutions were poured in the central wells of the plates, $1 \times$ PBS was poured in the surrounding wells in order to prevent evaporation from the samples. The kinetics of fibrillogenesis of gels prepared at $\mathrm{pH} 10$ was monitored by measuring the turbidity, defined here as the absorbance at $310 \mathrm{~nm}$, with a $\mu$ Quant Spectrophotometer (BioTek Instruments Inc., Highland Park, U.S.) and the related software KC4. The measurements were ended when the values of the absorbance stopped showing statistically significant changes. In order to evaluate the rate of fibrillogenesis, the half-time $\left(t_{1 / 2}\right)$, defined as the time at which the absorbance reached half of its final value, was calculated. Only the final absorbance, defined as the absorbance at the steady state, was measured in the case of gels prepared at $\mathrm{pH} 7$.

The different microstructures of collagen gels as a function of $\mathrm{pH}$ and ionic strength were observed by SEM. Collagen gel disks $(200 \mu \mathrm{L}, \varnothing=11 \mathrm{~mm})$ were prepared at different ionic strengths (c1, c4 or c7) and pHs (7 or 10) and set at $21^{\circ} \mathrm{C}$. Each combination of $\mathrm{pH}$ and ionic strength was repeated four times $(n=4)$. Samples were soaked in $1 \times$ PBS overnight, washed in $0.1 \mathrm{M}$ cacodylate buffer (sodium cacodylate trihydrate, Sigma Aldrich, St. Louis, MO, U.S.) and fixed at $4{ }^{\circ} \mathrm{C}$ for 2 hours with $2.5 \%$ glutaraldehyde (Sigma Aldrich, St. Louis, MO, U.S.) in $0.1 \mathrm{M}$ cacodylate buffer solution. After fixation, samples were rinsed with $0.1 \mathrm{M}$ cacodylate buffer and treated with $0.25 \%$ osmium tetroxide in $0.1 \mathrm{M}$ cacodylate buffer solution. Samples were rinsed once again at $4{ }^{\circ} \mathrm{C}$ with $0.1 \mathrm{M}$ cacodylate buffer, dehydrated at three different concentrations of ethanol (70, 95, 100\%), and dried with the critical point drying method (Polaron CPD 7501, VG Microtech, East Grinstead, W Sussex, UK). Samples were then sputter-coated with gold-palladium and images were captured with a scanning electron microscope JSM-35CF (Jeol Ltd., Tokyo, Japan).

Collagen solutions for all combinations of $\mathrm{pH}$ and ionic strength were poured into 48 multiwell plates (48 Well Cell Culture Cluster, Corning, NY, U.S.) and gelled at 4, 21 and $37{ }^{\circ} \mathrm{C}$. Each combination of $\mathrm{pH}$, ionic strength and temperature was repeated three times $(\mathrm{n}=3)$. The resulting cylindrical samples (height $=5.5 \mathrm{~mm}, \varnothing=11 \mathrm{~mm}$ ) were then soaked in $1 \times$ PBS overnight and tested in compression mode with a piston $(\varnothing=20 \mathrm{~mm})$ attached to a $5 \mathrm{~N}$ load cell and connected to an Instron 5848 Microtester (Instron Corporation, Norwood, MA, U.S.). Samples were preconditioned with three cycles $(0-2 \%)$ and tested at $0.2 \mathrm{~mm} / \mathrm{s}$ and room temperature. The mechanical behavior was evaluated by considering the compressive modulus (CM), defined as the linear regression between 15 and $30 \%$ of strain, and the compressive strain energy (CSE), defined as the integral of the curve between 0 and $40 \%$ of strain. The gel prepared at $\mathrm{pH} 7$, at an ionic strength corresponding to 4 and set at $37{ }^{\circ} \mathrm{C}$ was used as a control because, except for the concentration of collagen, it presented the same experimental conditions as the one previously studied in our laboratory [25].

Square-section toroidal samples (cross-sectional area: $5 \mathrm{~mm} \times 6 \mathrm{~mm}, \mathrm{I} . \mathrm{D} .=22 \mathrm{~mm}, \mathrm{n}=2$ ) were obtained by pouring collagen solutions in specific plastic molds and were tested in tensile mode in the same conditions as compression tests. Two black strips $(1 \mathrm{~mm} \times 5 \mathrm{~mm})$ were applied on the samples and the deformation was followed using a video camera. The mechanical behavior was evaluated in 
terms of tensile modulus (TM), defined as the linear regression of the final part of the curve before break, and ultimate tensile stress (UTS).

Collagen gels prepared at $\mathrm{pH} 10$ and three different ionic strengths (c1, c4 or c7) were set in 48 multiwell plates at the three different temperatures. Each combination of ionic strength and temperature was repeated three times $(n=3)$. Samples were then soaked overnight in $1 \times$ PBS and then in culture medium (79\% Dulbecco's Modified Eagle Medium (DMEM High Glucose, HyClone Laboratories Inc., Logan, UT, U.S.), 10\% Fetal Bovine Serum (FBS, Multicell Wisent Inc., Saint-Jean-Baptiste de Rouville, QC, Canada), 10\% Porcine Serum (PS, Multicell Wisent Inc., Saint-Jean-Baptiste de Rouville, QC, Canada) and 1\% Penicillin-Streptomycin (PenStrep, Invotrogen Corp., Carlsbad, CA, U.S.)). $3 \times$ E05 porcine smooth muscle cells (pSMCs) between the second and seventh passage were seeded on each sample and covered with culture medium. Samples were incubated and colorimetric assays were carried out after 24 or 48 h. 3-(4,5-dimethylthiazol-2-yl)-2,5-diphenyl-2H-tetrazolium bromide (MTT, Sigma Aldrich, St. Louis, MO, U.S.) is reduced to purple formazan by mitochondrial dehydrogenase in cells indicating normal cell metabolism. At each time point, culture medium was removed and each sample was rinsed with PBS in order to remove dead cells. MTT was solubilized in culture medium $(1 \mathrm{mg} / \mathrm{mL})$ and added to cells; samples were subsequently incubated for $4 \mathrm{~h}$. The medium was then removed, samples were extensively rinsed with $1 \times$ PBS and dried overnight in a vacuum oven at $21{ }^{\circ} \mathrm{C}$; the purple formazan crystals were solubilized with pure dimethyl sulfoxide (DMSO, Sigma Aldrich, St. Louis, MO, U.S.) at room temperature. The optical density at $595 \mathrm{~nm}$ was determined using a 96-well plate reader (BioRad Model 450 Microplate Reader, Mississauga, ON, Canada). Cell viability was expressed as \% of the control, corresponding in this case to the collagen gel previously developed and whose biological properties have already been assessed [7]. Even though this gel presented a lower concentration of collagen $(2 \mathrm{mg} / \mathrm{mL})$ because of the presence of serum and culture medium, it was considered the best choice as a positive control in order to evaluate the potential of the new gels in terms of biological performances.

ANOVA tests were carried out in order to evaluate statistically significant differences between treatments. Two-way and three-way ANOVA were used to analyze the results from turbidity measurements, compression and viability tests. The Tukey's test was adopted to analyze the results from tensile tests. Differences between treatments were considered statistically significant for $\mathrm{p}<0.05$. All the experiments were repeated at least twice and the results are expressed as mean \pm standard deviation (SD).

\section{Results and Discussion}

Collagen gels prepared at different pHs, ionic strengths and set at different temperatures were evaluated by turbidity measurements, mechanical tests and SEM imaging in order to assess the effects of these three factors on the process of self-assembly.

\subsection{Turbidity Measurements}

The results from the turbidity measurements are presented in Figure 1. For all the treatments, the absorbance increased with time and finally reached a plateau (Figure 1 $(\mathrm{a}-\mathrm{c})$ ). No syneresis was observed macroscopically. The value of this final absorbance was used to define the $t_{1 / 2}$ (Figure $2(d)$ ) and 
consequently to estimate the time required for gelation. In particular, it can be noticed that the increase of the absorbance or reaching of the plateau was delayed by increasing the ionic strength. On the contrary, an increase in the temperature led to a faster gelation.

The collagen gels prepared at c5, c6 or c7 and set at $\mathrm{T}=4{ }^{\circ} \mathrm{C}$ had not completely gelled by day 38 . They were held at $21^{\circ} \mathrm{C}(\mathrm{T} 1 *)$ and their turbidity increased and reached steady state in three days. In this case, the $t_{1 / 2}$ was extrapolated. The results regarding the final absorbance and the $t_{1 / 2}$ are presented in Table 2. The final absorbance was higher and the kinetics faster (data not shown) for gels prepared at $\mathrm{pH} 7$ than for gels prepared at $\mathrm{pH} 10$. In particular, collagen gels prepared at $\mathrm{pH} 7$ and set at $37{ }^{\circ} \mathrm{C}$ presented too many bubbles that invalidated the spectrophotometric measurements, so these results were not reported. This situation did not compromise other types of characterization and these samples were otherwise tested.

Figure 1. (a) Turbidity measurements for collagen gels prepared at $\mathrm{pH} 10$, different ionic strengths (c1, c2, c3, c4, c5, c6, c7) and $\mathrm{T}=4{ }^{\circ} \mathrm{C}$. (b) Turbidity measurements for collagen gels prepared at $\mathrm{pH} 10$, different ionic strengths (c1, c2, c3, c4, c5, c6, c7) and $\mathrm{T}=21^{\circ} \mathrm{C}$. (c) Turbidity measurements for collagen gels prepared at $\mathrm{pH} 10$, different ionic strengths (c1, c2, c3, c4, c5, c6, c7) and $\mathrm{T}=37^{\circ} \mathrm{C}$. (d) Example of $\mathrm{t}_{1 / 2}$ defined as the time required to reach half of the final absorbance.
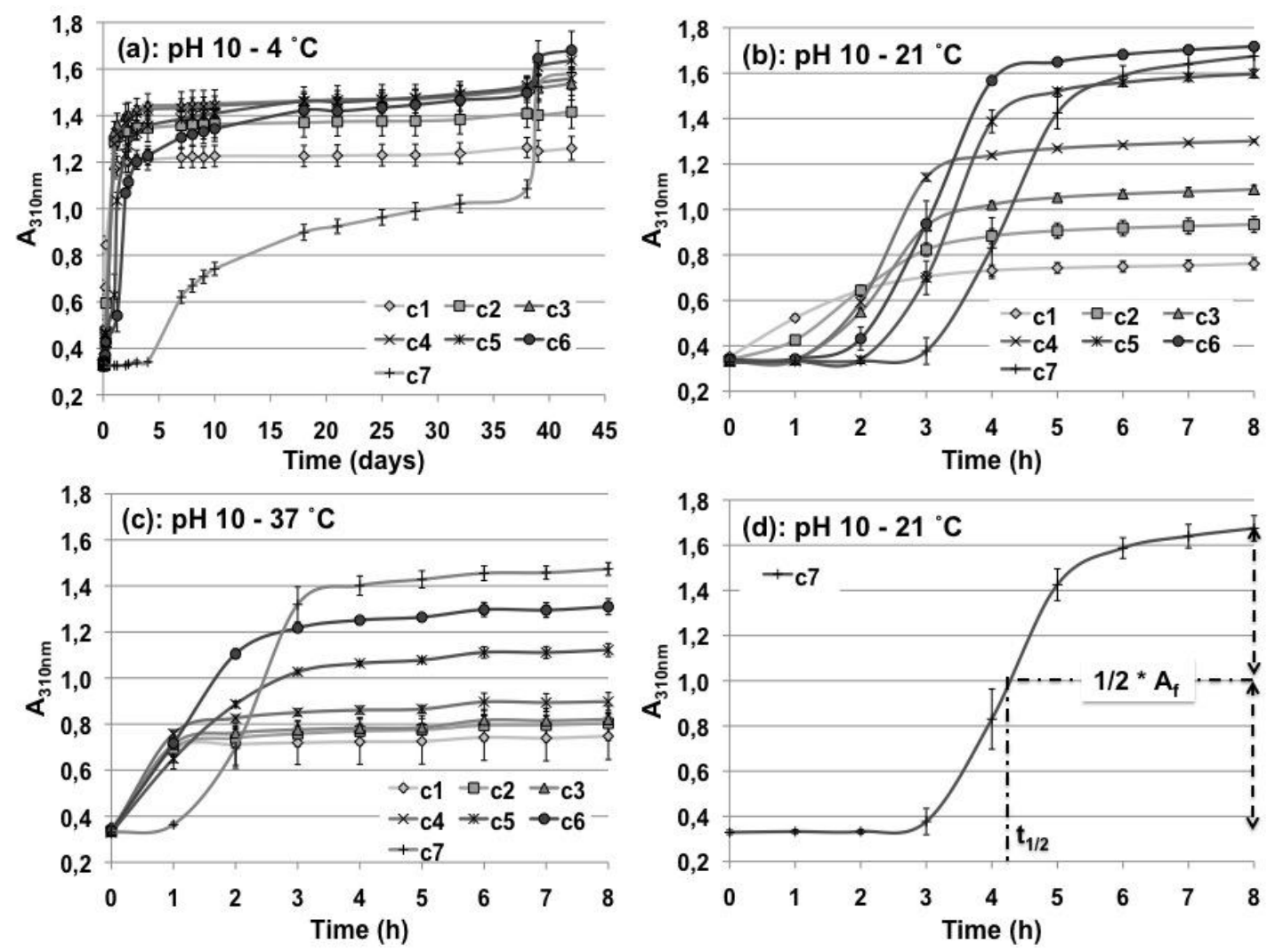
Figure 2. SEM images $(7200 \times)$ of samples prepared at different $\mathrm{pHs}$, ionic strengths and set at $\mathrm{T}=21^{\circ} \mathrm{C}$. (a) Sample prepared at $\mathrm{pH} 7$ and ionic strength c1. (b) Sample prepared at pH 7 and ionic strength c4. (c) Sample prepared at pH 7 and ionic strength c7. (d) Sample prepared at pH 10 and ionic strength c1. (e) Sample prepared at pH 10 and ionic strength c4. (f) Sample prepared at pH 10 and ionic strength c7.
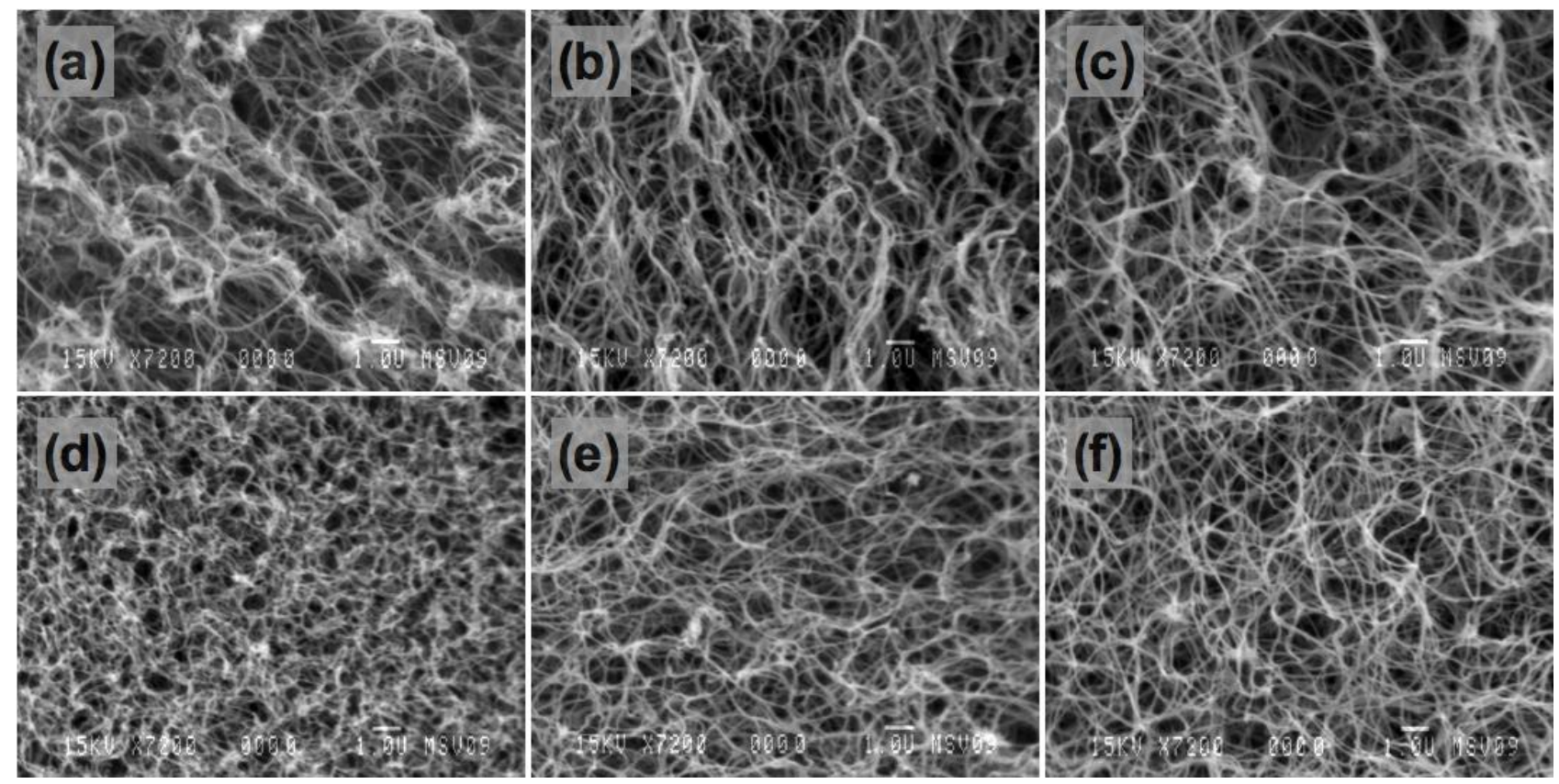

Table 2. Results from the turbidity measurements as a function of $\mathrm{pH}(7,10)$, ionic strength $(\mathrm{c} 1, \mathrm{c} 2, \mathrm{c} 3, \mathrm{c} 4, \mathrm{c} 5, \mathrm{c} 6, \mathrm{c} 7)$ and temperature $\left(\mathrm{T} 1=4{ }^{\circ} \mathrm{C}, \mathrm{T} 1 *=4{ }^{\circ} \mathrm{C}\right.$ and $21{ }^{\circ} \mathrm{C}$ after 38 days, $\mathrm{T} 2=21^{\circ} \mathrm{C}, \mathrm{T} 3=37^{\circ} \mathrm{C}$ ): Final absorbance for all the types of gels and $\mathrm{t}_{1 / 2}$ for gels prepared at $\mathrm{pH} 10$.

\begin{tabular}{c|cc|ccccccc}
\hline & \multicolumn{2}{|c|}{$\boldsymbol{p H} \mathbf{7}$} & \multicolumn{7}{c}{$\boldsymbol{p H ~ 1 0}$} \\
\hline & $\mathbf{A}_{\mathbf{3 1 0 n m}}(\mathbf{T 1})$ & $\mathbf{A}_{\mathbf{3 1 0 n m}}(\mathbf{T 2})$ & $\mathbf{A}_{\mathbf{3 1 0 n m}}(\mathbf{T 1})$ & $\mathbf{A}_{\mathbf{3 1 0 n m}}(\mathbf{T 1})$ & $\mathbf{t}_{\mathbf{1} / \mathbf{2}}$ & $\mathbf{A}_{\mathbf{3 1 0 n m}}(\mathbf{T 2})$ & $\mathbf{t}_{\mathbf{1} / \mathbf{2}}$ & $\mathbf{A}_{\mathbf{3 1 0 n m}}(\mathbf{T 3})$ & $\mathbf{t}_{\mathbf{1} / \mathbf{2}}$ \\
\hline $\mathbf{c 1}$ & $1.5 \pm 0.05$ & $1.60 \pm 0.07$ & $1.26 \pm 0.05$ & $1.26 \pm 0.04$ & $5.6 \mathrm{~h}$ & $0.79 \pm 0.03$ & $1.4 \mathrm{~h}$ & $0.8 \pm 0.12$ & $21 \mathrm{~min}$ \\
$\mathbf{c 2}$ & $1.76 \pm 0.02$ & $1.83 \pm 0.09$ & $1.41 \pm 0.07$ & $1.41 \pm 0.06$ & $9 \mathrm{~h}$ & $0.97 \pm 0.03$ & $2 \mathrm{~h}$ & $0.88 \pm 0.09$ & $33 \mathrm{~min}$ \\
$\mathbf{c 3}$ & $1.87 \pm 0.03$ & $1.96 \pm 0.03$ & $1.53 \pm 0.06$ & $1.51 \pm 0.05$ & $13 \mathrm{~h}$ & $1.13 \pm 0.02$ & $2.4 \mathrm{~h}$ & $0.86 \pm 0.01$ & $28 \mathrm{~min}$ \\
$\mathbf{c 4}$ & $2.00 \pm 0.02$ & $2.06 \pm 0.08$ & $1.55 \pm 0.04$ & $1.52 \pm 0.04$ & $14 \mathrm{~h}$ & $1.35 \pm 0.01$ & $2.4 \mathrm{~h}$ & $0.94 \pm 0.04$ & $31 \mathrm{~min}$ \\
$\mathbf{c 5}$ & $2.02 \pm 0.04$ & $2.10 \pm 0.02$ & $1.64 \pm 0.04$ & $1.53 \pm 0.04$ & $29 \mathrm{~h}$ & $1.66 \pm 0.02$ & $3.4 \mathrm{~h}$ & $1.21 \pm 0.03$ & $1.5 \mathrm{~h}$ \\
$\mathbf{c 6}$ & $2.18 \pm 0.03$ & $2.04 \pm 0.07$ & $1.68 \pm 0.08$ & $1.5 \pm 0.06$ & $44 \mathrm{~h}$ & $1.78 \pm 0.02$ & $3.2 \mathrm{~h}$ & $1.41 \pm 0.04$ & $1.35 \mathrm{~h}$ \\
$\mathbf{c 7}$ & $2.16 \pm 0.05$ & $2.14 \pm 0.05$ & $1.59 \pm 0.05$ & $1.09 \pm 0.04$ & $24 \mathrm{~d}$ & $1.78 \pm 0.06$ & $4.34 \mathrm{~h}$ & $1.54 \pm 0.03$ & $2.3 \mathrm{~h}$ \\
\hline
\end{tabular}

The kinetics of gels prepared at $\mathrm{pH} 7$ as a function of collagen concentration, temperature and ionic strength has already been widely discussed by several authors [23,24,30,31]. Considering that the conclusions of these authors were consistent with the results concerning the kinetics of gelation of samples prepared at $\mathrm{pH} 7$, it was chosen not to report them here in detail. In general, turbidity assays have already been used to assess collagen self-assembly in vitro [23,24,30,31]. In particular, Wood et al. and Williams et al. have already shown that the precipitation of collagen molecules is regulated by concentration, $\mathrm{pH}$, ionic strength and temperature [23,24]. Both authors showed that 
collagen self-assembly is faster at lower ionic strengths or at higher temperatures. On the contrary, these works presented different conclusions concerning the effects of $\mathrm{pH}$ (range 6-8) on gelation rate: Wood et al. stated that an increase of $\mathrm{pH}$ led to a decrease in the gelation rate while Williams et al. stated the opposite. It has to be considered that collagen gels were prepared at different concentrations: $1 \mathrm{mg} / \mathrm{mL}$ in the case of Wood et al. and $0.1 \mathrm{mg} / \mathrm{mL}$ in the case of Williams et al.

This work studied collagen gels prepared at a higher concentration $(2.8 \mathrm{mg} / \mathrm{mL})$ and a higher $\mathrm{pH}(10)$ than those discussed by the previously cited authors, and the results concerning the effects of temperature and ionic strength are consistent with both these works. In the case of the effect of $\mathrm{pH}$, the results presented here agree with the conclusions from Wood et al. [23]. All the factors had a statistically significant effect on gelation, in terms of kinetics or final absorbance $(p<0.05)$. The modulation of these three factors could make the $\mathrm{t}_{1 / 2}$ shift by several hours or days while the turbidity measures could change by a factor of three. The precipitation of collagen fibrils is an endothermic process whose rate increases with temperature [32]. This effect can be considered in terms of an increase of hydrophobic interactions due to an increase of temperature. As well, a decrease of ionic strength can prevent the phenomenon of salting in and enhance bonding between electrostatically charged amino acid side chains [20]. The difference in the gelation rate in some cases could be observed macroscopically by the presence of bubbles that generally remained trapped in the gel when gelation was completed in less than one hour. In general, samples prepared at lower $\mathrm{pH}$, lower temperature and higher ionic strength presented a higher turbidity, as observed by Wood et al. [23]. As discussed in the next section, these authors observed that gels with ticker fibrils caused by a lower $\mathrm{pH}$ or temperature or a higher ionic strength presented a higher turbidity. In order to show the effects of the three parameters on collagen gels microstructure, SEM analyses were carried out.

\subsection{SEM}

Figure 2 shows the microstructure of collagen gels as a function of $\mathrm{pH}$ and ionic strength, as imaged by SEM.

As can be observed, the microstructure of collagen gels changed as a function of $\mathrm{pH}$ and ionic strength. The matrices appear tighter at higher $\mathrm{pH}$ for all the considered levels of ionic strength. The same observation can be found in the work of Rosenblatt et al. [20]. This effect is probably due to the formation of net electrostatic interactions between charged residues, resulting in tighter packing of the fibrils.

Even though fibril diameters were not measured here, some observations can be made. For example, collagen fibrils of samples prepared at $\mathrm{c} 1$ seem to be thinner at both $\mathrm{pHs}$ when compared to the other gels prepared at $\mathrm{c} 4$ or $\mathrm{c} 7$ and the same $\mathrm{pH}$. At the same time, for $\mathrm{c} 1$ and $\mathrm{c} 4$, samples prepared at $\mathrm{pH} 7$ seem to present thicker fibrils than samples prepared at $\mathrm{pH} 10$.

Several authors have pointed out the importance of $\mathrm{pH}$, ionic strength and temperature in changing the dimensions of the fibrils and consequently the microstructure of collagen gels [21,23,24]. Roeder et al. showed that fibril diameter decreases at more basic $\mathrm{pH}$ values and Wood et al. showed that fibril diameter generally increases at lower $\mathrm{pH}$, higher ionic strength or lower temperature $[21,23]$. In particular, as discussed in the previous section, lower ionic strength and higher temperature increase electrostatic and hydrophobic interactions, which enhance fibril precipitation and limit lateral 
aggregation, resulting in thinner fibrils. The same authors observed that matrices with thicker fibrils resulted in higher turbidity as discussed in this work. Yang et al. and Raub et al. focused on the microstructure of collagen gels as a function of temperature [33,34]. In both cases, collagen gels were prepared at $\mathrm{pH} 7.4$ but at different concentrations: $2 \mathrm{mg} / \mathrm{mL}$ by Yang et al. and $4 \mathrm{mg} / \mathrm{mL}$ by Raub et al. While Yang et al. observed that fibrils were thinner at higher temperature; Raub et al. observed that fiber diameter increased at lower temperature. The difference in collagen concentration may explain why Raub et al. observed fibril bundles. The present work does not present SEM images for collagen gels prepared at $\mathrm{pH} 7$ and set at different temperatures. From the final absorbance results (Table 2), it can be observed that there were no significant differences between gels prepared at $\mathrm{pH} 7$ and set at different temperatures; consequently no major differences at the microstructural level could be assumed. In a following work, Raub et al. considered the effects of $\mathrm{pH}$ (range 5.5-8.5) on fiber size [35]. The authors observed that fiber diameter as well as the pore size and the pore area fraction decreased by increasing the $\mathrm{pH}$. While these considerations are regarding gels with a final collagen concentration of $4 \mathrm{mg} / \mathrm{mL}$, this work proposes similar conclusions concerning the effect of $\mathrm{pH}$ on the final microstructure, where slender and more tightly packed fibrils occur in the case of higher $\mathrm{pH}$.

The different organization and size of collagen fibrils resulted in microstructures with different mechanical properties.

\subsection{Mechanical Tests}

Figure 3 shows the typical mechanical behavior in the compression and tension of collagen gels as well as the slopes and the area under the curve used to define the parameters that have been adopted to compare the different treatments.

Figure 3. Mechanical behavior of collagen gels in terms of compression and tension with the slopes that were used to define the compressive modulus (CM) and tensile modulus (TM), respectively. The compressive strain energy (CSE) was defined as the integral between 0 and $40 \%$ of strain.

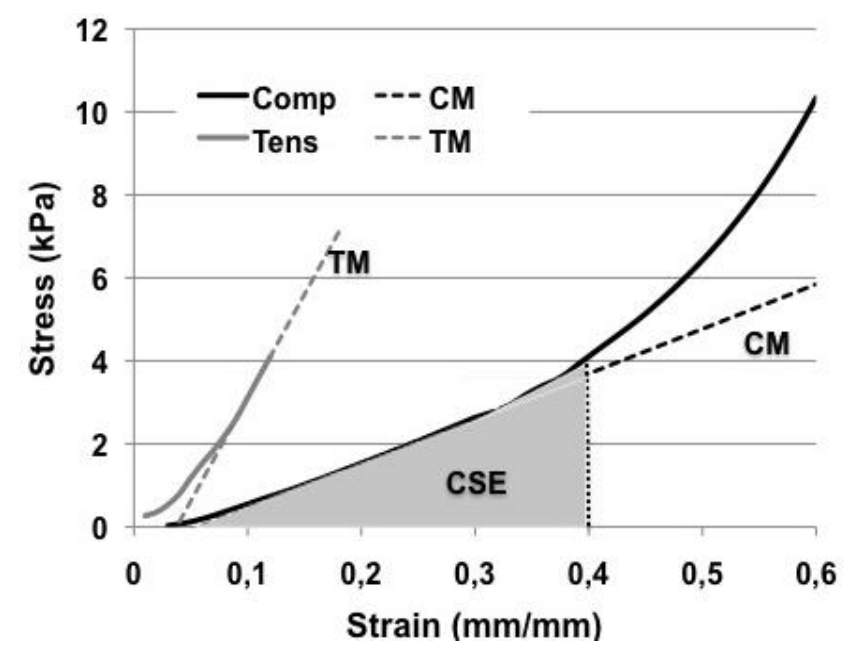

Both CM and TM were calculated out of the toe region that is typical of collagen-based materials $[15,21,28,36]$. The CM was defined between 15 and $30 \%$ of strain where a linear region 
could be identified for all the treatments, while the CSE was evaluated up to the $40 \%$ of strain because the approach of the piston to the plate was considered to affect the results for strain higher than $40 \%$. In this case, the presence of the toe region in the strain range in which the CSE was calculated did not affect the results. The results concerning the CM and CSE are presented in Figure 4 and restated in Table 3 as a function of ionic strength, $\mathrm{pH}$ and temperature.

Higher $\mathrm{pH}$, particularly at lower temperature, significantly increased both CM and CSE $(\mathrm{p}<0.01)$. At the same time, the interactions between the three factors and the effects of the ionic strength on the mechanical properties were statistically significant $(\mathrm{p}<0.05)$, which depended on the combination of temperature and $\mathrm{pH}$. Except for samples prepared at $\mathrm{pH} 10$ and set at $4{ }^{\circ} \mathrm{C}$, where the mechanical properties increased with the ionic strength, the samples generally presented a maximum for the ionic strengths corresponding to $\mathrm{c} 2-\mathrm{c} 3-\mathrm{c} 4$ for any level of temperature. The improvement of the mechanical properties of the gel prepared at $\mathrm{pH} 10, \mathrm{c} 7$ and $4{ }^{\circ} \mathrm{C}$ was almost four-fold when compared to the control, and almost six-times when compared to the gel with the lowest mechanical properties.

Figure 4. Compressive strain energy (CSE) (a) and compressive modulus (CM) (c) as a function of ionic strength (salt conc., c1, c2, c3, c4, c5, c6, c7) and temperature $\left(\mathrm{T} 1=4{ }^{\circ} \mathrm{C}\right.$, $\mathrm{T} 2=21^{\circ} \mathrm{C}, \mathrm{T} 3=37^{\circ} \mathrm{C}$ ) for samples prepared at $\mathrm{pH}$ 7. CSE (b) and CM (d) as a function of ionic strength (salt conc., c1, c2, c3, c4, c5, c6, c7) and temperature $\left(\mathrm{T} 1=4{ }^{\circ} \mathrm{C}\right.$, $\mathrm{T} 2=21^{\circ} \mathrm{C}, \mathrm{T} 3=37^{\circ} \mathrm{C}$ ) for samples prepared at $\mathrm{pH} 10$.
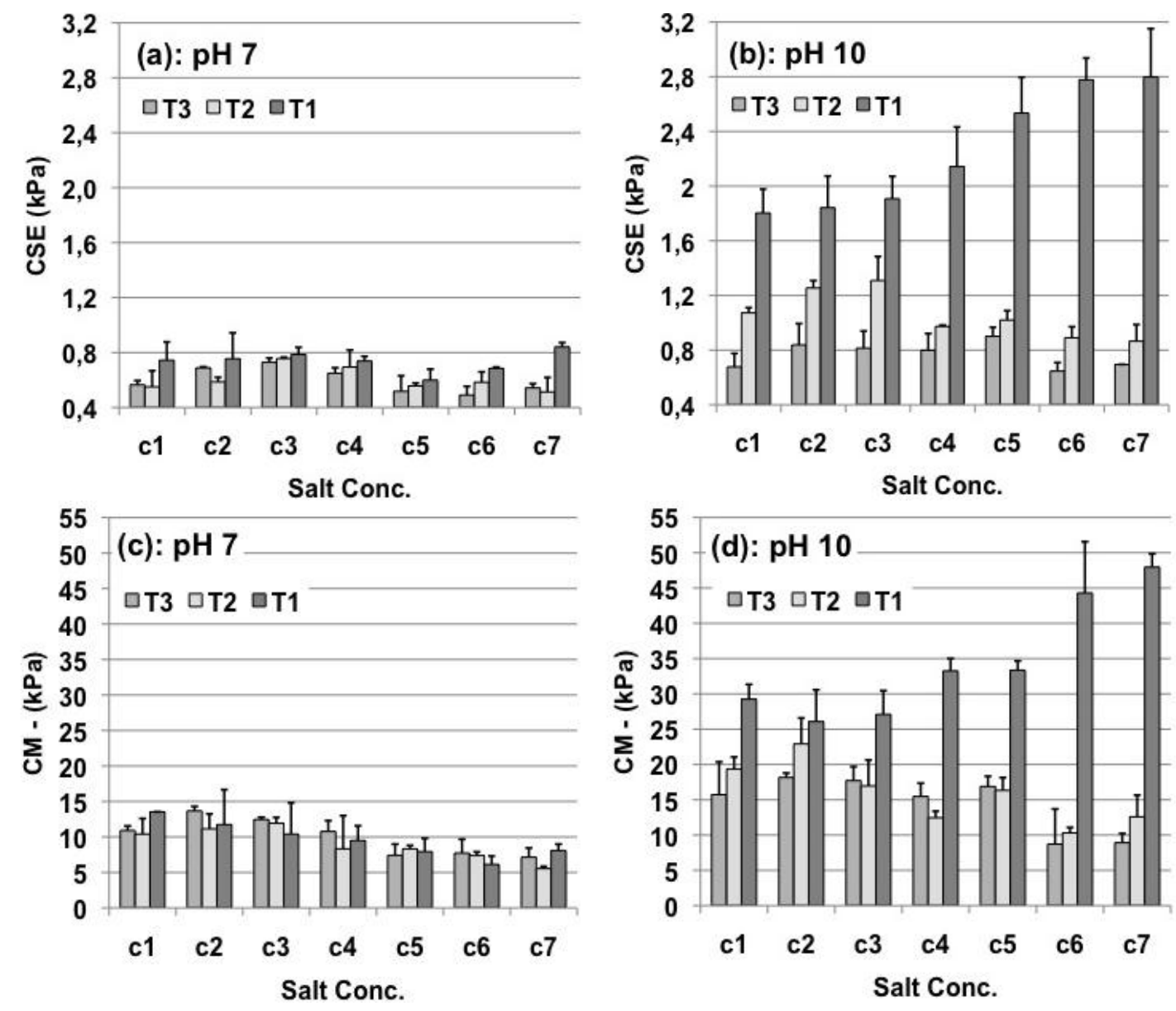
Table 3. CM and CSE as a function of ionic strength (c1, c2, c3, c4, c5, c6, c7), pH (7, 10) and temperature $\left(\mathrm{T} 1=4{ }^{\circ} \mathrm{C}, \mathrm{T} 2=21^{\circ} \mathrm{C}, \mathrm{T} 3=37^{\circ} \mathrm{C}\right)$ and expressed as mean $\pm \mathrm{SD}$.

\begin{tabular}{|c|c|c|c|c|c|c|}
\hline \multirow[b]{3}{*}{ Salt Conc. } & \multicolumn{6}{|c|}{$\mathrm{CM}(\mathbf{k P a})$} \\
\hline & \multicolumn{3}{|c|}{ pH 7} & \multicolumn{3}{|c|}{ pH 10} \\
\hline & $\mathbf{T 3}$ & $\mathbf{T} 2$ & T1 & T3 & $\mathbf{T} 2$ & T1 \\
\hline c1 & $10.91 \pm 0.63$ & $10.40 \pm 2.20$ & $13.54 \pm 0.004$ & $15.72 \pm 4.65$ & $19.36 \pm 1.70$ & $29.25 \pm 2.08$ \\
\hline c2 & $13.67 \pm 0.63$ & $11.14 \pm 2.11$ & $11.74 \pm 4.93$ & $18.16 \pm 0.63$ & $22.91 \pm 3.67$ & $26.08 \pm 4.51$ \\
\hline c3 & $12.47 \pm 0.31$ & $11.94 \pm 0.82$ & $10.4 \pm 4.42$ & $17.71 \pm 1.97$ & $16.97 \pm 3.67$ & $27.1 \pm 3.36$ \\
\hline c4 & $10.78 \pm 1.52$ & $8.33 \pm 4.68$ & $9.50 \pm 2.07$ & $15.46 \pm 1.89$ & $12.45 \pm 0.93$ & $33.26 \pm 1.75$ \\
\hline c5 & $7.41 \pm 1.58$ & $8.32 \pm 0.48$ & $7.93 \pm 1.87$ & $16.88 \pm 1.46$ & $16.33 \pm 1.82$ & $33.36 \pm 1.30$ \\
\hline c6 & $7.73 \pm 1.95$ & $7.39 \pm 0.51$ & $6.13 \pm 1.18$ & $8.72 \pm 4.97$ & $10.30 \pm 0.77$ & $44.3 \pm 7.27$ \\
\hline \multirow[t]{2}{*}{ c7 } & $7.15 \pm 1.3$ & $5.54 \pm 0.30$ & $8.09 \pm 0.89$ & $8.92 \pm 1.30$ & $12.59 \pm 3.06$ & $47.96 \pm 1.88$ \\
\hline & \multicolumn{6}{|c|}{ CSE (kPa) } \\
\hline c1 & $0.56 \pm 0.03$ & $0.55 \pm 0.12$ & $0.74 \pm 0.13$ & $0.68 \pm 0.1$ & $1.07 \pm 0.04$ & $1.80 \pm 0.17$ \\
\hline c2 & $0.69 \pm 0.01$ & $0.59 \pm 0.03$ & $0.75 \pm 0.19$ & $0.84 \pm 0.16$ & $1.25 \pm 0.05$ & $1.84 \pm 0.23$ \\
\hline c3 & $0.73 \pm 0.03$ & $0.76 \pm 0.01$ & $0.79 \pm 0.05$ & $0.81 \pm 0.12$ & $1.31 \pm 0.17$ & $1.91 \pm 0.16$ \\
\hline c4 & $0.65 \pm 0.04$ & $0.69 \pm 0.12$ & $0.74 \pm 0.03$ & $0.8 \pm 0.12$ & $0.97 \pm 0.01$ & $2.14 \pm 0.29$ \\
\hline c5 & $0.52 \pm 0.11$ & $0.56 \pm 0.02$ & $0.6 \pm 0.08$ & $0.90 \pm 0.07$ & $1.02 \pm 0.07$ & $2.53 \pm 0.26$ \\
\hline c6 & $0.49 \pm 0.06$ & $0.58 \pm 0.08$ & $0.68 \pm 0.01$ & $0.65 \pm 0.06$ & $0.89 \pm 0.08$ & $2.78 \pm 0.16$ \\
\hline c7 & $0.54 \pm 0.03$ & $0.51 \pm 0.11$ & $0.84 \pm 0.03$ & $0.69 \pm 0.001$ & $0.87 \pm 0.12$ & $2.8 \pm 0.35$ \\
\hline
\end{tabular}

Tensile tests were conducted only on the types of gel that were considered the most interesting in regard to the improvement of the mechanical properties shown in compression. Figure 5 presents the results in terms of TM and UTS.

Figure 5. (a) Tensile modulus (TM) of the most representative gels: * denotes treatments with statistically significant differences as compared to the control $(\mathrm{p}<0.01)$. (b) Ultimate tensile stress (UTS) of the most representative gels: * denotes treatments with statistically significant differences as compared to the control $(\mathrm{p}<0.05)$.


Considering the TM, the group of gels prepared at $\mathrm{pH} 10$ and set at $21{ }^{\circ} \mathrm{C}$ presented a maximum for c4. Consistent with the results from the compression tests (Figure 4(d)), collagen gels prepared at $\mathrm{pH} 10, \mathrm{c} 4$ and $21{ }^{\circ} \mathrm{C}$ as well as the gel prepared at $\mathrm{pH} 10, \mathrm{c} 7$ and $4{ }^{\circ} \mathrm{C}$, were significantly more 
resistant than the control ( $\mathrm{p}<0.01)$. Regarding the gel prepared at $\mathrm{pH} 10$, c7 and $4{ }^{\circ} \mathrm{C}$, the UTS was significantly higher than the one of the control $(\mathrm{p}<0.05)$.

As discussed in the previous section, several authors have studied the effects of parameters like $\mathrm{pH}$, ionic strength and temperature on fibrillogenesis [11,22-24,37]. Some of them already pointed out that, regarding the process of self-assembly, the modulation of these parameters can determine modifications at the micro-structural level in terms of the fibril size and the electrostatic interactions between neighboring fibrils [20,21,23,33-35,38]. Roeder et al. showed, in agreement with the conclusions from Wood et al., that the fibril diameter decreases and the fibril length increases by increasing the $\mathrm{pH}$, conjecturing that this change could explain the improvement in the mechanical properties $[21,23]$. While the mechanical properties increased as expected by increasing collagen concentration, collagen gels prepared at $2 \mathrm{mg} / \mathrm{mL}$ and different $\mathrm{pH}(6-9)$ were stiffer at higher $\mathrm{pH}$. The values of the linear modulus reported by these authors are lower than those presented in this work most probably for three reasons: a lower concentration of collagen in the gels, a lower $\mathrm{pH}$ during gel preparation and a lower testing rate. Rosenblatt et al. ( $\mathrm{pH}$ range 6-9) focused on the role of $\mathrm{pH}$ and ionic strength in generating collagen intermolecular attractive forces. These electrostatic forces finally stabilize the matrix yielding higher mechanical properties as shown by rheological tests [20]. Raub et al. ( $\mathrm{pH}$ range 5.5-8.5) confirmed by similar tests that collagen gels are stiffer when prepared at higher $\mathrm{pH}$ [35]. While it is difficult to compare the absolute values of the results of rheological tests with the ones of compression or tensile tests, it can be noted that the general conclusions about the effects of $\mathrm{pH}$ are consistent. Considering the findings of the previous section, the present study confirms that a more alkaline $\mathrm{pH}$ during gelation leads to a tighter packing of collagen fibrils and a more rigid microstructure. Even though the fibril diameter seems to decrease at higher $\mathrm{pH}$, a higher volume fraction of fibrils, more than the presence of thicker fibrils, may determine the increase of the mechanical properties, as proposed by the previously cited authors [21,34].

It has to be considered that while the present work reports the results of mechanical tests conducted on gels whose $\mathrm{pH}$ and ionic strength were stabilized at the physiological level by soaking the samples in $1 \times$ PBS, all the previously cited works discussed the mechanical properties of collagen gels prepared and tested at alkaline $\mathrm{pH}$. Because a higher $\mathrm{pH}$ implies more electrostatic bonds between fibrils, gels prepared and tested at alkaline $\mathrm{pH}$ values are expected to show higher mechanical properties than gels prepared at basic $\mathrm{pH}$ but then stabilized at $\mathrm{pH}$ 7-7.5.

Yang et al. and Raub et al. discussed the effects of temperature on the mechanical properties of collagen gels prepared at $\mathrm{pH} 7.4$ by rheological tests [33,34]. While Yang et al. observed that a temperature decrease resulted in higher stiffness, Raub et al. showed that gel stiffness decreased by decreasing the temperature. These works differed in the final concentration of collagen in the samples tested, 2 and $4 \mathrm{mg} / \mathrm{mL}$ respectively. In this work, from the results of the compression tests, no significant differences were observed between gels prepared at $\mathrm{pH} 7$ as a function of temperature. On the contrary, the temperature profoundly affected the mechanical properties of gel prepared at $\mathrm{pH} 10$.

Seliktar et al., Berglund et al. and Cummings et al. discussed the mechanical properties of collagen-based constructs under tensile tests [15,27,28]. The values of the tensile modulus of cell-compacted collagen gels without crosslinking, sleeves or support, are interestingly close to those reported in this work. In this case, cell-driven remodeling has yet not occurred and the mechanical properties could be further increased. 
Another factor that could partially explain the difference of mechanical properties observed between gels prepared at different $\mathrm{pHs}$, ionic strengths or temperatures, is the presence of air bubbles. These bubbles could remain trapped in the case of rapid gelation $(<1 \mathrm{~h})$, resulting in discontinuities in the structure and preferential sites for fracture propagation.

The present study was mainly devoted to define collagen gels that could satisfy the mechanical requirements following the pulsatile flow of a bioreactor $[39,40]$. In particular, during the early stages of conditioning, a collagen gel-based construct should resist up to $10 \mathrm{kPa}$ of circumferential stress and present a linear region with a circumferential modulus of at least $100 \mathrm{kPa}$. As can be observed in Figure 5, collagen gels prepared at $\mathrm{pH} 10, \mathrm{c} 7$ and $4{ }^{\circ} \mathrm{C}$ and gels prepared at $\mathrm{pH} 10,21^{\circ} \mathrm{C}$ and $\mathrm{c} 4$ or $\mathrm{c} 7$, present TM and UTS equal or higher than 100 and $10 \mathrm{kPa}$, respectively. On the contrary, the gels prepared under physiological conditions (control) do not satisfy these requirements.

In conclusion, although further attention should be addressed to the mechanical behavior of these constructs after several cycles, the collagen gels proposed in this work represent a valid scaffolding system to support cell proliferation and remodeling during the early stages of maturation in a bioreactor.

\subsection{Viability Test}

Viability tests were conducted only on gels prepared at $\mathrm{pH} 10$ because they were the most interesting considering their higher mechanical properties. These tests were carried out in order to validate the potential of these scaffolds to support cell adhesion and proliferation once they are installed in a bioreactor. The results of the MTT test are shown in Figure 6.

Figure 6. Results of the MTT test on collagen gel prepared at $\mathrm{pH} 10$ as a function of ionic strength, temperature of gelation and the time point ( 24 or $48 \mathrm{~h}$ ) at which cell viability was assessed. The results are expressed as \% cell viability of the control.



Cell viability did not significantly change as a function of ionic strength or the temperature at which samples were prepared, neither as a function of the time point. The viability of pSMCs on any type of gel seemed to be lower when compared to the control, at almost $80 \%$. This could be explained by two differences regarding the preparation of collagen gels and the preparation of the control. The control was gelled with culture medium and serum already inside. Even if the collagen gels discussed here 
were rinsed with culture medium, they could not be expected to have equivalent diffusion with these components. Moreover, the control had a final concentration of $2 \mathrm{mg} / \mathrm{mL}$ of collagen while the other gels had a final concentration of $2.8 \mathrm{mg} / \mathrm{mL}$. These tighter matrices could have diminished cell infiltration and proliferation. Notwithstanding this point, the gels presented in this work seem compatible with cell adhesion and proliferation.

\section{Conclusions}

The aim of this work was to improve the mechanical properties of collagen gels that are expected to support vascular cell adhesion and proliferation under dynamic conditioning. This could be achieved by increasing $\mathrm{pH}$, lowering temperature and modulating ionic strength.

In particular, this work focused on the effects of preparing collagen gels at $\mathrm{pH} 10$ and the interactions of this parameter with different levels of temperature or ionic strength. As shown by turbidity measurements and SEM, these parameters affected collagen self-assembly and consequently, the microstructure. Collagen fibril packing, in particular, became more important at higher $\mathrm{pH}$. These tighter matrices proved to be stiffer with significant increases in the compressive and tensile modulus as well as in compressive strain energy and ultimate tensile stress. The values of the tensile modulus were comparable to those of cellularized collagen gel. All the gels were tested under physiological conditions and the results of the mechanical tests confirmed the importance of different experimental conditions at the moment of collagen preparation. Collagen gel prepared at $\mathrm{pH} 10$ showed increasing mechanical properties when set at $4{ }^{\circ} \mathrm{C}$ as a function of ionic strength. In particular, collagen gels prepared at $\mathrm{pH} 10,174 \mathrm{mM}$ and set at $4{ }^{\circ} \mathrm{C}$ presented the highest mechanical properties. Among others, this work proposes an interesting method to tailor not only the mechanical properties but also the gelation time, which can be considerably increased by increasing the ionic strength of gels set at $4{ }^{\circ} \mathrm{C}$.

Further improvements can be obtained. While biological molecules like glycosaminoglycans can be added in order to favor cell proliferation as well as to further increase the mechanical properties in combination with chemical cross-linkers, the mechanical properties of collagen gels should be evaluated under cyclic testing in order to better mimic the cyclic solicitations imposed by the bioreactor to the vascular construct.

In conclusion, while all the collagen gels supported pSMC proliferation, some of them showed interesting mechanical properties, and therefore express a great potential as scaffolds for pSMCs in VTE applications.

\section{Acknowledgements}

We would like to thank Pascale Chevallier, Stéphane Turgeon and Jean Lagueux, at the Laboratory for Biomaterials and Bioengineering (LBB), for their kind help regarding the SEM, and Frédéric Couet, at Laval University, and Raquel Weska, at the University of Campinas, Brasil, in training at LBB, for their assistance in revising the article. We also acknowledge the Canadian Bureau for International Education (CBIE) for the award during the first year of Ph.D., the Natural Science and Engineering Research Council of Canada, the Canadian Institutes for Health Research and the Centre Hospitalier Universitaire de Québec, Hopital Saint-François d'Assise for partially funding this research. 


\section{References}

1. WHO Fact Sheet $\mathrm{N}^{\circ}$ 317-Cardiovascular Diseases. Available online: http://www.who.int/ mediacentre/factsheets/fs317/en/index.html (accessed on 5 July 2010).

2. Kannan, R.Y.; Salacinski, H.J.; Butler, P.E.; Hamilton, G.; Seifalian, A.M. Current Status of Prosthetic Bypass Grafts: A Review. J. Biomed. Mat. Res. B Appl. Biomater. 2005, 74B, 570-581.

3. Ratcliffe, A. Tissue Engineering of Vascular Grafts. Matrix Biol. 2000, 19, 353-357.

4. Isenberg, B.C.; Williams, C.; Tranquillo, R.T. Small-Diameter Artificial Arteries Engineered in vitro. Circ. Res. 2006, 98, 25-35.

5. Kakisis, J.D.; Liapis, C.D.; Breuer, C.; Sumpio, B.E. Artificial Blood Vessel: The Holy Grail of Peripheral Vascular Surgery. J. Vasc. Surg. 2005, 41, 349-354.

6. Chevallay, B.; Herbage, D. Collagen-Based Biomaterials as 3D Scaffold for Cell Cultures: Applications for Tissue Engineering and Gene Therapy. Med. Biol. Eng. Comput. 2000, 38, 211-218.

7. Boccafoschi, F.; Habermehl, J.; Vesentini, S.; Mantovani, D. Biological Performances of Collagen-Based Scaffolds for Vascular Tissue Engineering. Biomaterials 2005, 26, 7410-7417.

8. Gelse, K.; Poschl, E.; Aigner, T. Collagens-Structure, Function, and Biosynthesis. Adv. Drug Deliv. Rev. 2003, 55, 1531-1546.

9. Voet, D.; Voet, J.G. Three-Dimensional Structures of Proteins-Fibrous Proteins-Collagen. In Biochemistry, 3rd ed.; John Wiley and Sons Inc.: Hoboken, NJ, USA, 2004; pp. 233-239.

10. Rajan, N.; Habermehl, J.; Cote, M.-F.; Doillon, C.J.; Mantovani, D. Preparation of Ready-to-Use, Storable and Reconstituted Type I Collagen from Rat Tail Tendon for Tissue Engineering Applications. Nat. Protoc. 2007, 1, 2753-2758.

11. Silver, F.H.; Freeman, J.W.; Seehra, G.P. Collagen Self-Assembly and the Development of Tendon Mechanical Properties. J. Biomech. 2003, 36, 1529-1553.

12. Boccafoschi, F.; Rajan, N.; Habermehl, J.; Mantovani, D. Preparation and Characterization of a Scaffold for Vascular Tissue Engineering by Direct-Assembling of Collagen and Cells in a Cylindrical Geometry. Macromol. Biosci. 2007, 7, 719-726.

13. Habermehl, J.; Skopinska, J.; Boccafoschi, F.; Sionkowska, A.; Kaczmarek, H.; Laroche, G.; Mantovani, D. Preparation of Ready-to-Use, Stockable and Reconstituted Collagen. Macromol. Biosci. 2005, 5, 821-828.

14. Atala, A.; Lanza, R.P. Methods of Tissue Engineering; Academic Press: London, UK, 2002.

15. Seliktar, D.; Black, A.R.; Vito, R.P.; Nerem, R.M. Dynamic Mechanical Conditioning of Collagen-Gel Blood Vessel Constructs Induces Remodeling in vitro. Ann. Biomed. Eng. 2000, 28, 351-362.

16. Niklason, L.E.; Gao, J.; Abbott, W.M.; Hirschi, K.K.; Houser, S.; Marini, R.; Langer, R. Functional Arteries Grown in vitro. Science 1999, 284, 489-493.

17. Beckman, M.J.; Shields, K.J.; Diegelmann, R.F. Collagen. In Encyclopedia of Biomaterials and Biomedical Engineering; Marcel Dekker, Inc.: New York, NY, USA, 2004; pp. 324-334.

18. Yang, Y.-L.; Kaufman, L.J. Rheology and Confocal Reflectance Microscopy as Probes of Mechanical Properties and Structure during Collagen and Collagen/Hyaluronan Self-Assembly. Biophys. J. 2009, 96, 1566-1585. 
19. Wood, G.C. The Formation of Fibrils from Collagen Solutions. A Mechanism of Collagen-Fibril Formation. Biochem. J. 1960, 75, 598-605.

20. Rosenblatt, J.; Devereux, B.; Wallace, D.G. Injectable Collagen as a pH-Sensitive Hydrogel. Biomaterials 1994, 15, 985-995.

21. Roeder, B.A.; Kokini, K.; Sturgis, J.E.; Robinson, J.P.; Voytik-Harbin, S.L. Tensile Mechanical Properties of Three-Dimensional Type I Collagen Extracellular Matrices with Varied Microstructure. J. Biomed. Eng. 2002, 124, 214-222.

22. Gobeaux, F.; Mosser, G.; Anglo, A.; Panine, P.; Davidson, P.; Giraud-Guille, M.M.; Belamie, E. Fibrillogenesis in Dense Collagen Solutions: A Physicochemical Study. J. Mol. Biol. 2008, 376, 1509-1522.

23. Wood, G.C.; Keech, M.K. The Formation of Fibrils from Collagen Solutions-The Effect of Experimental Conditions: Kinetic and Electron-Microscope Studies Biochem. J. 1960, 75, 588-598.

24. Williams, B.R.; Gelman, R.A.; Poppke, D.C.; Piez, K.A. Collagen Fibril Formation. Optimal in vitro Conditions and Preliminary Kinetic Results. J. Biol. Chem. 1978, 253, 6578-6585.

25. Achilli, M.; Lagueux, J.; Mantovani, D. On the Effects of UV-C and $\mathrm{pH}$ on the Mechanical Behavior, Molecular Conformation and Cell Viability of Collagen-Based Scaffold for Vascular Tissue Engineering. Macromol. Biosci. 2010, 10, 307-316.

26. Couet, F.; Rajan, N.; Mantovani, D. Macromolecular Biomaterials for Scaffold-based Vascular Tissue Engineering. Macromol. Biosci. 2007, 7, 701-718.

27. Cummings, C.L.; Gawlitta, D.; Nerem, R.M.; Stegemann, J.P. Properties of Engineered Vascular Constructs Made from Collagen, Fibrin, and Collagen-Fibrin Mixtures. Biomaterials 2004, 25, 3699-3706.

28. Berglund, J.D.; Mohseni, M.M.; Nerem, R.M.; Sambanis, A. A Biological Hybrid Model for Collagen-Based Tissue Engineered Vascular Constructs. Biomaterials 2003, 24, 1241-1254.

29. Koob, T.J. Collagen Fixation. In Encyclopedia of Biomaterials and Biomedical Engineering; Marcel Dekker: New York, NY, USA, 2004; pp. 335-347.

30. Helseth, D.L., Jr; Veis, A. Collagen Self-Assembly in vitro. Differentiating Specific Telopeptide-Dependent Interactions Using Selective Enzyme Modification and the Addition of Free Amino Telopeptide. J. Biol. Chem. 1981, 256, 7118-7128.

31. Na, G.; Butz, L.; Carroll, R. Mechanism of in vitro Collagen Fibril Assembly. Kinetic and Morphological Studies. J. Biol. Chem. 1986, 261, 12290-12299.

32. Cooper, A. Thermodynamic Studies of the Assembly in vitro of Native Collagen Fibrils. Biochem. J. 1970, 118, 355-365.

33. Yang, Y.-L.; Leone, L.M.; Kaufman, L.J. Elastic Moduli of Collagen Gels Can Be Predicted from Two-Dimensional Confocal Microscopy. Biophys. J. 2009, 97, 2051-2060.

34. Raub, C.B.; Suresh, V.; Krasieva, T.; Lyubovitsky, J.; Mih, J.D.; Putnam, A.J.; Tromberg, B.J.; George, S.C. Noninvasive Assessment of Collagen Gel Microstructure and Mechanics Using Multiphoton Microscopy. Biophys. J. 2007, 92, 2212-2222.

35. Raub, C.B.; Unruh, J.; Suresh, V.; Krasieva, T.; Lindmo, T.; Gratton, E.; Tromberg, B.J.; George, S.C. Image Correlation Spectroscopy of Multiphoton Images Correlates with Collagen Mechanical Properties. Biophys. J. 2008, 94, 2361-2373. 
36. Gentleman, E.; Lay, A.N.; Dickerson, D.A.; Nauman, E.A.; Livesay, G.A.; Dee, K.C. Mechanical Characterization of Collagen Fibers and Scaffolds for Tissue Engineering. Biomaterials 2003, 24, 3805-3813.

37. Harris, J.R.; Reiber, A. Influence of Saline and $\mathrm{pH}$ on Collagen Type I Fibrillogenesis in vitro: Fibril Polymorphism and Colloidal Gold Labelling. Micron 2007, 38, 513-521.

38. Rosenblatt, J.; Devereux, B.; Wallace, D.G. Effect of Electrostatic Forces on the Dynamic Rheological Properties of Injectable Collagen Biomaterials. Biomaterials 1992, 13, 878-886.

39. Couet, F.; Mantovani, D. How to Optimize Maturation in a Bioreactor for Vascular Tissue Engineering: Focus on a Decision Algorithm for Experimental Planning. Ann. Biomed. Eng. 2010, 38, 2877-2884.

40. Bilodeau, K.; Couet, F.; Boccafoschi, F.; Mantovani, D. Design of a Perfusion Bioreactor Specific to the Regeneration of Vascular Tissues Under Mechanical Stresses. Artif. Organs 2005, 29, 906-922.

(C) 2010 by the authors; licensee MDPI, Basel, Switzerland. This article is an open access article distributed under the terms and conditions of the Creative Commons Attribution license (http://creativecommons.org/licenses/by/3.0/). 